\title{
Urban Screen and Spatial Dimension
}

\author{
Litta Primasari $^{1}$ \& Basauli Umar Lubis ${ }^{2}$ \\ ${ }^{1}$ Art Science and Design Program, Bandung Institute of Technology, \\ Jalan Ganesa No. 10, Bandung 40132, Indonesia \\ ${ }^{2}$ Department of Architecture, School of Architecture, Planning and Policy Development, \\ Bandung Institute of Technology, Jalan Ganesa No. 10, Bandung 40132, Indonesia \\ Email: littapsr@yahoo.co.id
}

\begin{abstract}
This paper is discussing about the urban screen phenomena and its influence to spatial dimension in urban space. The visual characteristics which are forming a spatial dimension will be an emphasis to be presented. Urban screen as a visual intervention has an impact to spatial configuration in urban space. The space dimension was not dominated with materiality limitation, but also images. We have to consider that people senses can measure a spatial dimension, knowing as a perception. That is a human visual and mind relation. The spatial dimension has no longer tangible boundary, but also has intangible ones. Spatial dimension in urban screens phenomena is not merely mathematics, nor spatial dimension in physics which are based on a three-dimensional Cartesian coordinate system. Movement can be expressed in other terms, by how far we can move depends on our eyes to catch that space limitation, and how fast we can move is depends on our mind to perceive some visual phenomenon, that is a spatial dimension. So, the dimension will depend on a visual quality that we perceived. The movement of the body and people's thought will be an important term to generate the space dimension in urban screen phenomenon. The activity of body's movement and thought will influence the depth of space dimension.
\end{abstract}

Keywords: new media; spatiality; urban screen; urban space; visual quality.

\section{$1 \quad$ Introduction}

Urban screens are various new digital display technologies that are being introduced into the urban landscape: daylight compatible LED billboards, plasma screens exposed in shop windows, beam boards, information displays in public transport systems, electronic city information terminals, holographic screen projections, or dynamic and intelligent surfaces, integrated into architectural facade structures [1]. This paper describes the LED big screen as a media which is placed in outdoor urban space and their potency to be read as a spatial dimension.

Although media may conjure up almost in many forms, virtually can only displace but not replace reality, whilst seeking to reaffirm the true meaning of being embodied. New spaces emerge and disappear, they overlap and

Received July $5^{\text {th }}, 2010$, Revised October $29^{\text {th }}, 2013$, Accepted for publication November $8^{\text {th }}, 2013$.

Copyright (C) 2013 Published by LPPM ITB, ISSN: 1978-3078, DOI: 10.5614/itbj.vad.2013.4.2.5 
interpenetrate one another, with the virtual city being at once a transmutation of the known, whilst standing alongside and being interwoven into real urban life [2].

As a screen media, urban screens are rectangular LED screens attached to buildings which predominately show traditional advertising, not taking into account that the urban screen is a different medium to the TV set. The urban screens are rectangular LED screens attached to buildings which predominately show traditional advertising, not taking into account that the urban screen is a different medium to the TV set. McCarthy [3] recognizes of the site-specificity of the TV screen. It concerns the materialization of place consequent of a dialogue between the ontological (space-binding) and geographical (the social, economic and political forces that shape physical space) notion of the screen. Inherent to the site-specificity of screens is a content-specificity. The content is plural in manifestation, but the general intent (commercial, informative, social or other) singular. Equally, it must not be overlooked that the material presence of the screen also shapes the physical space. The dynamic interfaces have the potential to "mobilize" static architectural structures and change the visual appearance and experience of the city. Media becomes a new landscape.

\section{The Dynamic of Urban Landscape}

The urban representation involves materials, visual and physic forms, and cannot reduce to textually. In the urban landscape, the (public) buildings and modern art, such as urban screen surrounding it would function as scenery for whatever would take place there. Mass demonstrations, for instance, in analogy to the fireworks, water ballets, and light and sound shows that had taken place during the world exhibition of Paris 1937 and New York of 1939. The most crucial change is the disappearance of the masses, who that could act collectively. The media, increased mobility, and the sprawling of the cities played a crucial role in this process.

The presence of urban screen is making a new spatial character enrich in urban setting.

\section{The Emerging of New Spatial Dimension}

The urban screen phenomenon could be viewed through a common visual reading, such as size, colour, brightness, composition, relationship, etc. But some of these need a critical visual analysis to catch the deeper dimension. There are several dimension possibilities that will emerge when we try to describe the urban screen phenomenon. 


\subsection{Screen as a Media}

The screen media work silently to influence the way in which we interact with one another, and with our society at large. In another word, that influence comprises everything we don't notice. If one thinks about it, there are far more dynamic processes occurring in the ground than comprise the actions of the figures, or things that we do notice. But when something changes, it often becomes noticeable. And noticing change is the key. McLuhan [4] tells us that a "message" is, "the change of scale or pace or pattern" that a new invention or innovation "introduces into human affairs". That it is not the content or use of the innovation, but the change in inter-personal dynamics that the innovation brings with it.

The personal and social consequences of any medium - that is, of any extension of our selves, result from the new scale that is introduced into our affairs by each extension of ourselves, or by any new technology. "The medium is the message" tell us that noticing change in our societal or cultural ground conditions indicates the presence of a new message, that is, the effects of a new medium.

\subsection{The Temporary Places}

Non-places are recent phenomenon when we experience the urban space with new media screen in it. Non-places mean that somewhere have no historical trajectory that embed the place with "meaning" and "identity." They are thereby less able to themselves offer satisfying "experiences." They conform to a neutral, or non-historical, aesthetics that establishes its void identity. Passing through the non-place you assume the role of a passenger, customer or driver and lose your identity as an individual [5]. The pause in passenger flow leads is the accumulation of perceptual, cognitive and physical monotony. Interpreting Augé's concept, Bolter and Grusin [6] define non-places as high-technology spaces; "free floating, hyper-mediated experiences" and claim that the media within the non-place define its identity. The screens in non-places are granted identity with the substitution of the non-experience for an experience.

\subsection{Contribute to Placelessness}

A non-places experience at the same time will generate the autonomous individuals and homogeneous public [3]. That is a condition when people experiencing a visual distracted, shifting, a montage. McCarthy calls this as a multiple- viewing position which is a capability to separate selves with another and their surrounding through spectatorship. The screen is always a barrier, a distance, between the space of the viewer and the immaterial content of the screen. Nevertheless, these distance showed us the relationship between the 
space of the viewer and the space of representation through screen that exists in our normal space.

\subsection{Illumination}

The illumination has an important rule to generate a spatial dimension of urban screen in the urban landscape, especially at night. Scott McQuire [7] states that the alteration of customary relations of dimension, distance and materiality created a strange environment under influence if lights. The apparent loss of physical solidity, the rapid alteration of scale and proportion, the blurring of edges and the intermingling and overlapping of previously discrete spaces intensified the ambiguous relations between reality and fantasy. But such fantasy was rapidly becoming part of daily life. Electric light not only illuminates but intoxicated, doubling and redoubling the city, recreating its buildings, streetscapes and squares as floating, de-materialized zones. The ambient spaces were often transient, susceptible to sudden transformation or equally sudden disappearance.

\subsection{Cultural Sensory}

The movement of the body and people's thought will be an important term to generate the space dimension in urban screen phenomena. The information that was received from human receptor system (visual, auditory, olfactory, kinesthetic, tactile, thermal perception of space) is modified by culture. The activity of body's movement and thought will influence the depth of space dimension.

Vision is the most important and complex receptor. Vision is synthesis. It is not passive but active, a transaction between a person and her/his environment. A person learns while he sees and what he learns influences what he sees. There is a visual field (retinal image) and a visual world (what is perceived). Perceptual worlds vary between people and between cultures. This influences their manner of orienting themselves in space, and how they get around. So to speak, the dimension will depends on a visual quality that we perceived.

\section{The Form of Spatial Dimension}

The relationship between the space of the viewer and the space of representation through screen will generate a kind of form of mixed-reality space which is overlapping, interrelating and blending each other. There are eclectic space, hybrid space, and mutation space. Figure 1 showing us the map of mixedreality space form that present in several cities. 
The eclectic space describes the blending of space possibility but every structure still has reference with their previous meaning. In this space, the relation between architectural and screen space only indicated the existence togetherness. People can feel their existence as a separated structure that generate distracting, shifting, montage, and shocking phenomenon. The eclectic space majoring occurs in several cities.

The hybrid space is creates the blending space quietly. The structure will be difficult to separating each other because of their relationship. The screen needs an architectural structure to be existed. But especially at night, the architectural space already disappeared and it would be replaced by the screen space.

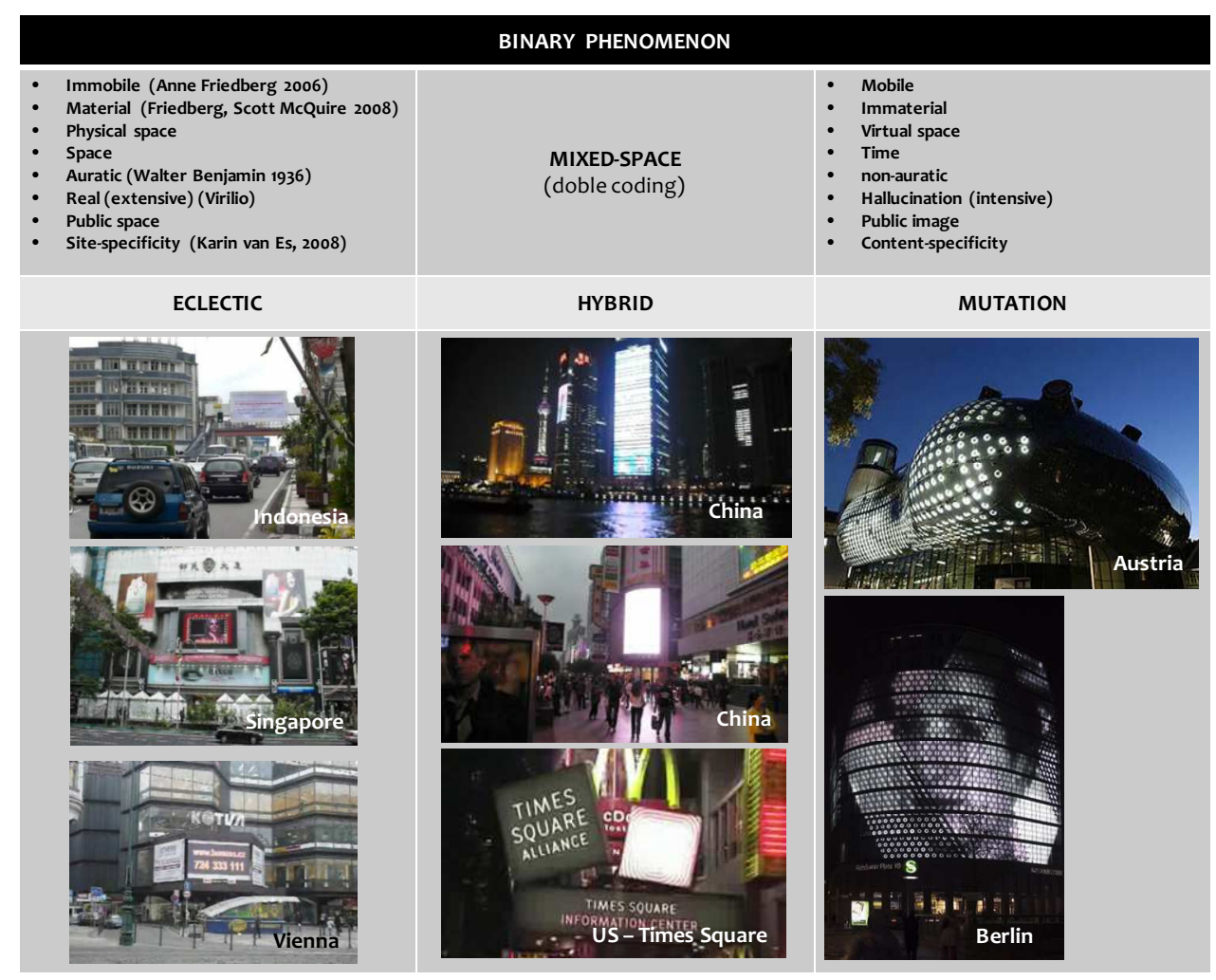

Figure 1 The illustration of mixed-space position in several cities.

The mutation space will occur when each structure not able to separate. It appearance could be traced as a new form and loosed their ancestor meaning. In 
the other word, the disappearance of it space that mean vanish of architectural and screen space. The screens have formed the urban landscape.

The urban screen phenomenon is always present a binary condition which is influence and interpenetrated each other. This calls it phenomenon as a mixedspace or double-coding. The eclectic space has the smallest influence to space surround it. The screen is only performs a content of information and advertisement to public. The differences with hybrid space are laid on their levels of influence to public space. The hybrid space already to richness the space around it with the screen which is not only performs the information but also a public visual art.

The mutation space generates a new space which is displaces an existing space. This blending space was creates by embedness of architectural space and screen. At the other word, the screen is a particular element to form the architectural space.

\section{Conclusion}

The emergence of new spatial dimension which is media screen take place will enrich a spatial character and should be considered as a new urban landscape. In several cities in Indonesia, the urban screen should be accepted as a new formation of technology, following the emerging uses of LED panel in urban space around the world.

In this case, the content needs to be considered with new visions of how, when, and in what specific locations screens can be integrated in the urban landscape and its architecture. The synergy between content, location, and type of screen determines the interaction with the audience and prevents noise and visual pollution. Furthermore, we need to understand how the growing infrastructure of digital displays influences the perception of our public spaces and visual sphere.

\section{References}

[1] Struppek, M. 2006. Urban Screens-The urbane potential of public screens for interaction, Accessed from http://www.intelligentagent.com/ archive/Vol6_No2_interactivecity_struppek.htm, Intelligent Agent, 6(2), Special Issue: Papers presented at the ISEA2006 Symposium.

[2] Fahmi, W.S. 2006. The Urban Incubator: (De)Constructive (Re)Presentation of Heterotopia Spatiality and Virtual Image(Ries), First Monday, Special Issue\#4: Urban Screen: Discovering the Potential of Outdoor Screens for Urban Society. 
[3] McCarthy, A. 2003. Ambient Television: Visual Culture and Public Space, $2^{\text {nd }}$ Ed., Durham: Duke University Press.

[4] McLuhan, M. 1964. Understanding Media: The Extensions of Man, New York: McGraw Hill.

[5] Augé, M. 1995. Non-Places: Introduction to An Anthropology of Supermodernity, Trans. John Howe, London-New York: Verso.

[6] Bolter, J.D. \& Grusin, R. 1999. Remediation: Understanding New Media, Cambridge, MA: The MIT Press.

[7] McQuire, S. 2008. The Media City: Media, Architecture and Urban Space, Sage Publication, London. 